\title{
Transcatheter left atrial appendage occlusion for stroke prevention in patients with atrial fibrillation: results from the Belgian registry
}

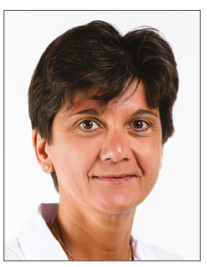

Joelle Kefer ${ }^{*}$, MD, PhD; Adel Aminian², MD; Paul Vermeersch³, MD, PhD;

Tom de Potter ${ }^{4}, \mathrm{MD}$; Francis Stammen 5 , MD; Edouard Benit ${ }^{6}, \mathrm{MD}$; Werner Budts 7 , MD, PhD;

Luc Missault $^{8}, \mathrm{MD}, \mathrm{DSc}$; Benny Drieghe ${ }^{9}$, MD; Ian Buysschaert ${ }^{10}, \mathrm{MD}, \mathrm{PhD}$;

Kristoff Cornelis ${ }^{11}$, MD; Jean-Manuel Herzet ${ }^{12}$, MD; Antoine Guedes ${ }^{13}, \mathrm{MD}, \mathrm{PhD}$;

Nadia Debbas ${ }^{14}$, MD, PhD; Maximo Rivero ${ }^{15}$, MD; Mathieu Lempereur ${ }^{16}, \mathrm{MD}, \mathrm{PhD}$; Stijn Lochy ${ }^{17}$, MD; Ruben Casado-Arroyo $^{18}$, MD; Christophe Laruelle ${ }^{19}$, MD; Philippe Debruyne ${ }^{20}$, MD; Thierry Ledent ${ }^{21}$, MD

1. Cliniques Universitaires Saint-Luc, Brussels, Belgium; 2. CHU Charleroi, Charleroi, Belgium; 3. Middelheim ZNA, Antwerp, Belgium; 4. OLV Ziekenhuis, Aalst, Belgium; 5. AZ Delta Roeselare, Roeselare, Belgium; 6. Jessaziekenhuis, Hasselt, Belgium;

7. Gasthuisberg UZ Leuven, Leuven, Belgium; 8. AZ Sint-Jan, Bruges, Belgium; 9. UZ Gent, Gent, Belgium; 10. ASZ Aalst, Aalst, Belgium; 11. Marie Middelares, Gent, Belgium; 12. CHR Citadelle, Liège, Belgium; 13. CHU UcL Namur, Yvoir, Belgium;

14. CHU St-Pierre, Brussels, Belgium; 15. Ziekenhuis Oost-Limburg, Genk, Belgium; 16. CHU Liège, Liège, Belgium;

17. UZBrussel, Brussels, Belgium; 18. Erasme ULB, Brussels, Belgium; 19. St-Luc Bouge, Bouge, Belgium; 20. Imelda

Ziekenhuis, Bonheiden, Belgium; 21. CHU Tivoli, La Louvière, Belgium

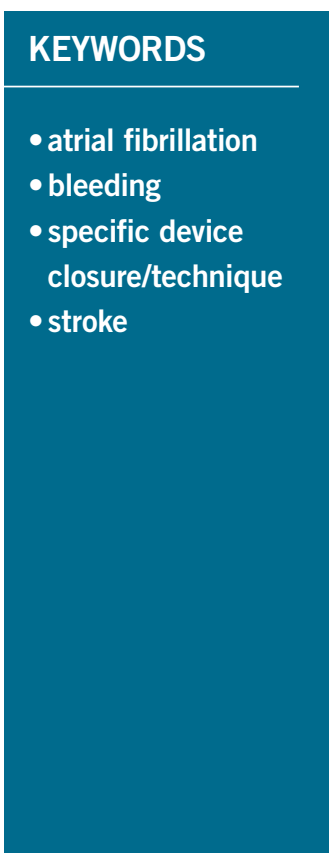

\section{Abstract}

Aims: This study aimed to assess the safety and efficacy at midterm follow-up of left atrial appendage occlusion (LAAO) using different devices, in real life in Belgium.

Methods and results: Between June 2009 and November 2016, 457 consecutive patients (63\% male, $75 \pm 12$ yrs, $\mathrm{CHA}_{2} \mathrm{DS}_{2}$-VASc $4 \pm 0.6$, HAS-BLED $3.5 \pm 0.7$ ) undergoing LAAO were included. Technical success was $97.1 \%$. There were 19 periprocedural major adverse events $(4.1 \%)$ including three deaths $(0.6 \%)$, nine tamponades $(1.9 \%)$, four major bleedings $(0.8 \%)$ and two device embolisations $(0.4 \%)$. Among patients successfully implanted having a complete follow-up (672 patient-years, median follow-up 370 days), the actual annual stroke rate was $1.2 \%$, lower than the expected stroke risk of $4 \%$ ( $70 \%$ reduction). The observed bleeding rate was $2 \%$, while the calculated risk was $3.7 \%$ (46\% reduction). KaplanMeier analysis showed a similar overall survival $(93 \pm 2 \%$ and $87 \pm 3 \%$ versus $91 \pm 3 \%$ and $87 \pm 4 \%$; $=0.35$ ) and event-free survival $(92 \pm 2 \%$ and $84 \pm 3 \%$ versus $88 \pm 3 \%$ and $80 \pm 5 \%$; $\mathrm{p}=0.17)$ at one and two years, for the ACP/Amulet versus the WATCHMAN groups of patients, respectively.

Conclusions: The data from the Belgian left atrial appendage occlusion registry suggest that the procedure is effective and relatively safe in a real-world setting, using either the WATCHMAN or the ACP/Amulet device.

\footnotetext{
*Corresponding author: Division of Cardiology, Cliniques Universitaires Saint-Luc, Avenue Hippocrate, 10-2881, 1200 Brussels,
} Belgium.E-mail:joelle.kefer@uclouvain.be 


\section{Abbreviations}

$\begin{array}{ll}\text { ACP } & \text { AMPLATZER Cardiac Plug } \\ \text { AF } & \text { atrial fibrillation } \\ \text { DAPT } & \text { dual antiplatelet therapy } \\ \text { LAAO } & \text { left atrial appendage occlusion } \\ \text { MAE } & \text { major adverse events } \\ \text { NOAC } & \text { new oral anticoagulant } \\ \text { NS } & \text { not significant } \\ \text { OAC } & \text { oral anticoagulant } \\ \text { TEE } & \text { transoesophageal echocardiography } \\ \text { TIA } & \text { transient ischaemic attack }\end{array}$

\section{Introduction}

Transcatheter percutaneous left atrial appendage occlusion (LAAO) is an alternative therapeutic option for stroke prevention in patients with atrial fibrillation $(\mathrm{AF})^{1-4}$. LAAO has been demonstrated to be non-inferior to warfarin in two randomised controlled trials that included only patients without contraindications to oral anticoagulants (OACs) $)^{5,6}$. Large observational studies described the safety and short-term outcome after using only one device ${ }^{7-14}$. Until now, there have been no randomised trials comparing the results of the currently available prostheses. Real-world data on the long-term safety and efficacy of LAAO using different device technologies are limited $^{15,16}$. The aim of our study was to collect the baseline, procedural and follow-up characteristics of patients undergoing LAAO in Belgium, and to assess the safety and efficacy of the procedure in the real world of patients not candidates for long-term OAC, allowing a comparison of the different types of device used.

\section{Methods}

Between June 2009 and November 2016, 457 consecutive patients undergoing LAAO in 21 centres in Belgium were prospectively included in the registry. Demographics, baseline characteristics, indications for LAAO, $\mathrm{CHA}_{2} \mathrm{DS}_{2}$-VASc and HAS-BLED scores, antithrombotic medication, procedural details, periprocedural adverse events and clinical follow-up were prospectively collected in a dedicated database. The protocol was approved by the Ethics Committee of the Université Catholique de Louvain. Three different devices available in Belgium were implanted according to operator preference - the AMPLATZER ${ }^{\text {TM }}$ Cardiac Plug (ACP), the AMPLATZER $^{\mathrm{TM}}$ Amulet $^{\mathrm{TM}}$ (both St. Jude Medical, St. Paul, MN, USA) and the WATCHMAN ${ }^{\circledR}$ (Boston Scientific, Marlborough, MA, USA). The results of the first 90 patients implanted with the ACP device have been reported previously ${ }^{10}$.

\section{DEFINITIONS OF SUCCESS}

According to the Munich consensus document ${ }^{17}$, device success was defined as successful implantation of the device in the correct position. Technical success is a device success with no large leak and no devicerelated complications. Device-related complications are embolisation, erosion, interference with surrounding structures, thrombus, fracture, infection, perforation or allergy. Procedural success is a technical success without any major periprocedural complications.

\section{PERIPROCEDURAL COMPLICATIONS}

Periprocedural complications (occurring during zero to seven days after the procedure or before hospital discharge, whichever was last) included death, myocardial infarction, stroke, transient ischaemic attack (TIA) according to VARC criteria ${ }^{18}$, systemic embolism, air embolism, device embolisation, major bleeding according to the BARC 3 and 5 criteria $^{19}$, and cardiac tamponade.

Periprocedural major adverse events (MAE) included death, stroke, systemic embolism and complication requiring major surgical or endovascular intervention (major bleeding, tamponade, device migration treated by snare or surgery) occurring between zero and seven days post procedure or before hospital discharge, whichever was last.

\section{CLINICAL FOLLOW-UP}

Patient survival and clinical events during the follow-up were determined by review of medical records or phone contact of patients implanted successfully. Adverse events during followup included death (cardiovascular or non-cardiovascular), stroke, TIA, systemic embolism, major bleeding, tamponade, myocardial infarction, and device-related complications. Antithrombotic medication was recorded at discharge and at last follow-up visit.

\section{EFFICACY ON STROKE, TIA, SYSTEMIC EMBOLISM AND BLEEDING PREVENTION}

LAAO efficacy on thromboembolism and bleeding prevention was tested by comparing the actual event rate with the predicted event rate by the $\mathrm{CHA}_{2} \mathrm{DS}_{2}$-VASc or HAS-BLED score, respectively ${ }^{20,21}$. Event reduction was calculated as follows - (estimated $\%$ - actual $\%$ event rate)/estimated $\%$ event rate.

\section{ECHOCARDIOGRAPHY}

Patients underwent a transoesophageal echocardiography (TEE) during the procedure allowing the grading of the potential residual leak after implantation. Despite the fact that several definitions have been proposed over time ${ }^{3,8-10}$, in the current study, according to the Munich consensus document, residual leak was graded using the width of the Doppler colour jet as none (absence of colour jet), mild (1-5 mm) or large ( $>5 \mathrm{~mm})$ for all devices.

\section{STATISTICAL ANALYSIS}

Continuous variables are presented as mean \pm 1 standard deviation. Categorical variables are presented as counts and percentages. Continuous variables were tested using the independent samples t-test and categorical variables using Fisher's exact test.

Univariate and multivariate analysis was carried out using the Cox proportional hazards method. Variables with a $\mathrm{p}<0.10$ at univariate analysis were included in the backward stepwise multivariate analysis. Estimates for freedom from the composite of death and MAE were obtained by the Kaplan-Meier estimation method. A p-value $<0.05$ was considered statistically significant. Analyses were performed using SPSS version 15.0 (SPSS Inc., Chicago, IL, USA). 


\section{Results}

\section{PATIENTS}

A total of 457 patients were included in the database and constituted the total cohort of the study. Baseline characteristics are listed in Table 1. The distribution of the $\mathrm{CHA}_{2} \mathrm{DS}_{2}-\mathrm{VASc}$ and HASBLED scores is detailed in Figure 1. The mean $\mathrm{CHA}_{2} \mathrm{DS}_{2}$-VASc (4.6 \pm 1.6$)$ and HAS-BLED (3.2 \pm 1$)$ scores were not significantly different between patients treated by ACP/Amulet (Group 1) and those undergoing a WATCHMAN implantation (Group 2; $4.5 \pm 1.7$ and $3.1 \pm 1$, respectively; $\mathrm{p}=\mathrm{NS}$ ). Patients in Group 1 more frequently experienced a previous major bleeding but had less diabetes mellitus than those in Group 2.

Indications for the procedure in Belgium were mainly previous major bleeding (gastrointestinal and cerebral in 136 and 134 patients, respectively). The other reasons for LAAO were recurrent minor bleeding in $27 \%$, recurrent stroke under anticoagulation in $11 \%$ and other cause in $18 \%$ of cases.

\section{PROCEDURE}

Procedures were performed in 21 centres reporting by themselves their complete data from the beginning (first implants were not excluded from the study). Only three centres performed more than 50 procedures, while six others started the LAAO programme in 2016. The device implanted was ACP in 174 patients, Amulet in 144 and WATCHMAN in 139 cases. One hundred and sixty-eight patients $(37 \%)$ were in sinus rhythm at the time of implantation. An additional procedure was combined in $22 \%$ of cases - 93 coronary angiography, 11 atrial fibrillation ablation and one interatrial septal defect closure. The outcome of the patients was similar between patients with and those without a combined intervention. Device
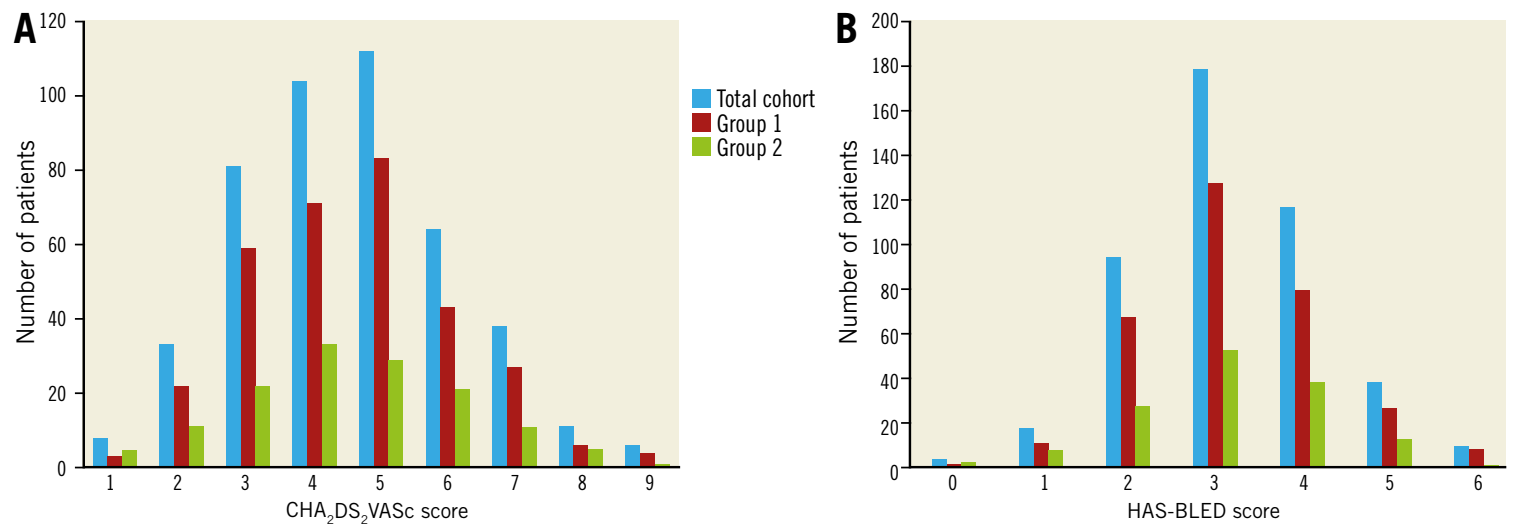

Figure 1. Distribution of the CHA $D S_{2}-V A S c$ (A) and the HAS-BLED (B) scores observed in the total cohort (in blue), Group 1 (in red), and Group 2 (in green).

Table 1. Baseline characteristics.

\begin{tabular}{|c|c|c|c|c|c|c|c|}
\hline \multicolumn{2}{|l|}{ Characteristics } & $\begin{array}{c}\text { All } \\
N=457\end{array}$ & $\begin{array}{c}\text { ACP } \\
N=174\end{array}$ & $\begin{array}{l}\text { Amulet } \\
N=144\end{array}$ & $\begin{array}{c}\text { Group } 1 \\
\text { ACP+Amulet } \\
\mathrm{N}=318\end{array}$ & $\begin{array}{c}\text { Group } 2 \\
\text { WATCHMAN } \\
N=139\end{array}$ & $p$-value \\
\hline Age (yrs) & mean \pm SD & $75 \pm 12$ & $74 \pm 7$ & $77 \pm 8$ & $75 \pm 7$ & $75 \pm 8$ & 0.74 \\
\hline Gender & $\mathrm{M} / \mathrm{F}$ & $288 / 169$ & $112 / 62$ & $82 / 62$ & $194 / 124$ & $94 / 45$ & 0.20 \\
\hline Congestive heart failure & $\mathrm{n}(\%)$ & $110(24)$ & $38(22)$ & $37(26)$ & $75(24)$ & $35(25)$ & 0.72 \\
\hline Hypertension & $\mathrm{n}(\%)$ & $357(78)$ & $131(75)$ & $121(84)$ & $252(79)$ & $105(75)$ & 0.39 \\
\hline Diabetes & $\mathrm{n}(\%)$ & $123(27)$ & $43(25)$ & $33(23)$ & $76(24)$ & 47 (34) & 0.03 \\
\hline Vascular disease & $\mathrm{n}(\%)$ & $172(38)$ & $64(37)$ & $52(36)$ & $116(36)$ & $56(40)$ & 0.46 \\
\hline Previous stroke/TIA & $\mathrm{n}(\%)$ & $203(44)$ & $75(43)$ & $71(49)$ & $146(46)$ & $57(41)$ & 0.35 \\
\hline Previous major bleeding & $\mathrm{n}(\%)$ & $365(80)$ & $138(79)$ & $126(87)$ & $264(83)$ & $101(73)$ & 0.01 \\
\hline Permanent AF & $\mathrm{n}(\%)$ & $267(58)$ & $96(55)$ & $86(60)$ & $182(57)$ & $85(61)$ & 0.94 \\
\hline Serum creatinine $(\mathrm{mg} / \mathrm{dl})$ & mean $\pm S D$ & $1.2 \pm 0.7$ & $1.1 \pm 0.4$ & $1.4 \pm 1$ & $1.3 \pm 0.8$ & $1.2 \pm 0.5$ & 0.78 \\
\hline $\mathrm{CHADS}_{2}$ score & mean $\pm S D$ & $2.8 \pm 1.3$ & $2.7 \pm 1.3$ & $3 \pm 1.2$ & $2.8 \pm 1.3$ & $2.7 \pm 1.3$ & 0.75 \\
\hline $\mathrm{CHA}_{2} \mathrm{DS}_{2}$-VASc score & mean $\pm \mathrm{SD}$ & $4 \pm 0$ & $4.5 \pm 1.6$ & $4.7 \pm 1.5$ & $4.6 \pm 1.6$ & $4.5 \pm 1.7$ & 0.96 \\
\hline HAS-BLED score & mean $\pm S D$ & $3.5 \pm 0.7$ & $3.3 \pm 1.2$ & $3.1 \pm 0.9$ & $3.2 \pm 1$ & $3.1 \pm 1.1$ & 0.86 \\
\hline
\end{tabular}


success was achieved in 97.5\%; 11 device failures were reported due to inappropriate anatomy, four with the ACP device, zero with the Amulet and seven with the WATCHMAN. Large residual leak was observed after two WATCHMAN implantations $(0.4 \%$ of the total cohort); technical success was achieved in $97.1 \%$.

\section{PERIPROCEDURAL COMPLICATIONS}

The rate of periprocedural MAE was $4.1 \%$ (Table 2). Three procedural deaths occurred $(0.6 \%)$, all related to tamponades treated by surgery but ultimately resulting in death. Additional tamponades were observed in nine cases: four of them were successfully treated by a percutaneous pericardiocentesis and five required surgery. There were significantly more MAE with the ACP device than after Amulet implantation ( $4.5 \%$ versus $0.7 \%, \mathrm{p}=0.04)$, explained by the learning curve (centres started with the ACP and moved to the Amulet when it became available). Two device embolisations were reported: one was totally asymptomatic, discovered at day 1 and successfully retrieved by snare. The other one required a surgical removal of the implant with a good outcome. Major bleedings occurred only in Group 2 (four versus zero, $\mathrm{p}=0.008$ ) - two groin haematoma and two recurrent bleedings (one from the lung, the other one from gastrointestinal angiodysplasia) still recurrent despite stopping anticoagulants after LAAO. Dual antiplatelet therapy (DAPT) was used in three of them, while the last one was under aspirin alone. This is the only statistically significant difference between Groups 1 and 2, but it is numerically not clinically relevant. There was no incidence of periprocedural stroke, TIA or myocardial infarction in our cohort. Procedural success was achieved in $96.6 \%$ of cases.

Medications at discharge were mainly DAPT, prescribed in $72 \%$ of cases (Figure 2A). Any form of anticoagulant therapy was more frequently used after WATCHMAN (24\%) than after ACP/ Amulet implantation (3\%). Eighty-eight percent of patients were left untreated by any anticoagulant at discharge after LAAO.

\section{FOLLOW-UP}

The follow-up was complete in 417 of 444 patients with successful LAAO (94\%). The mean duration of follow-up was 589 days, and the median value was 12.3 months (interquartile range 136841 days), resulting in a total of 672 patient-years. There were 10 strokes (eight ischaemic, two haemorrhagic), seven TIAs, three fatal bleedings, nine major bleedings reported during the followup period, with no difference between groups (Table 3). Among the 49 deaths observed during this period, 14 were from an identified cardiovascular disease (Table 4). Only one death was procedure-related due to a delayed device embolisation at one month
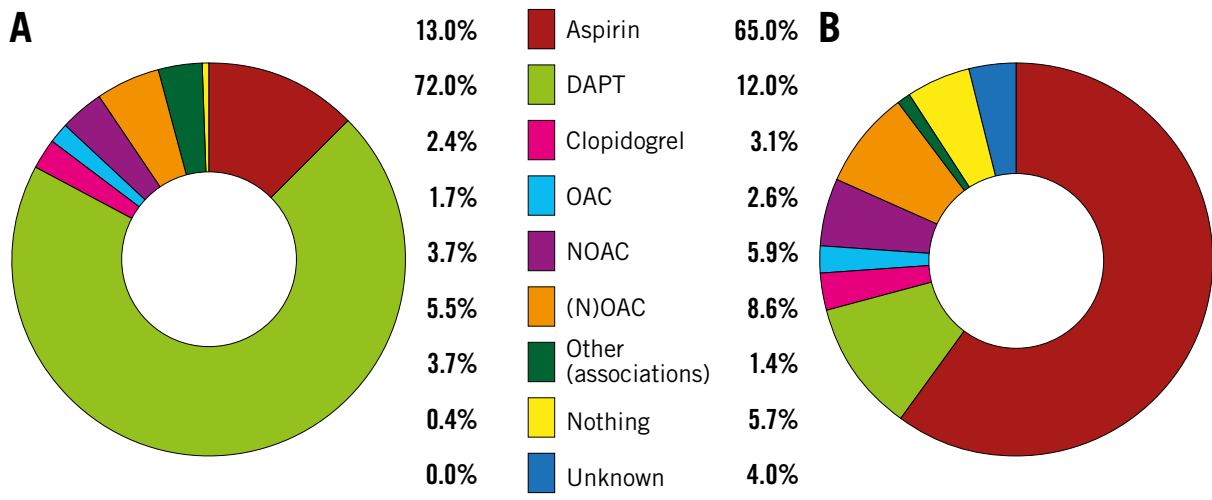

Figure 2. Medications given. A) At discharge. B) At last follow-up. DAPT: dual antiplatelet therapy; NOAC: new oral anticoagulant; (N)OAC: any form of anticoagulant; OAC: oral anticoagulant

Table 2. Periprocedural complications.

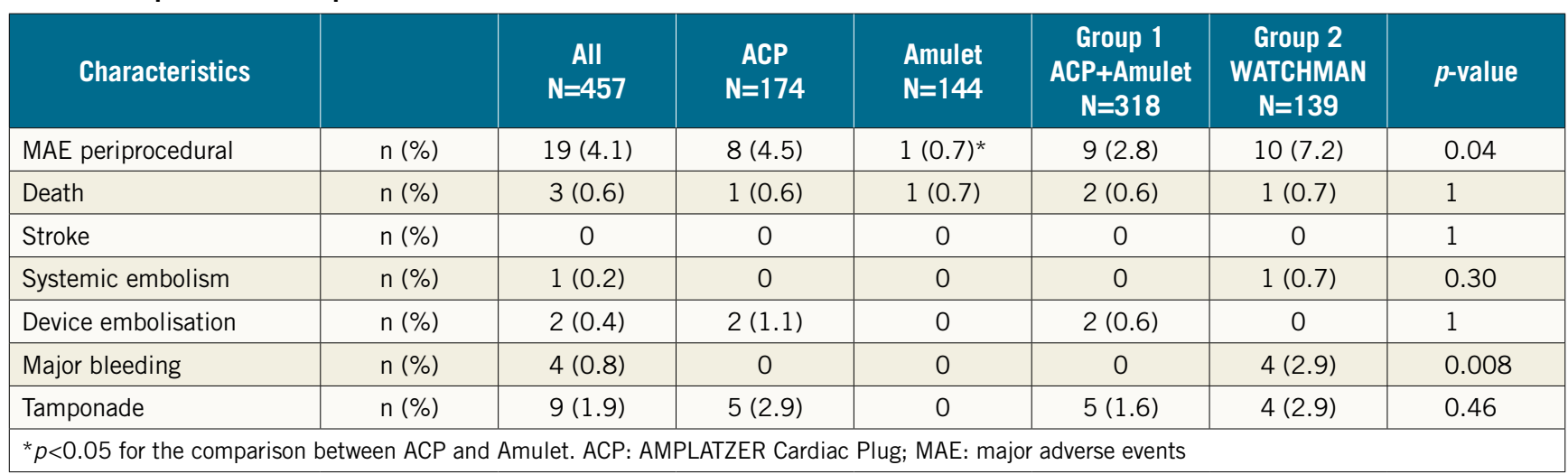


after an uneventful ACP implantation, treated by emergent surgery but resulting in death. The vast majority of deaths were related to the comorbidities of patients and occurred at a mean time of 594 (median 406) days after the procedure.

Overall survival of the total cohort was $89 \pm 2 \%$ (Figure 3). Kaplan-Meier analysis showed a similar overall and event-free survival, for the WATCHMAN versus the ACP/Amulet groups of patients, respectively (Figure 4).

In univariate analysis, $\mathrm{CHA}_{2} \mathrm{DS}_{2} \mathrm{VASc}$ score, HAS-BLED score, congestive heart failure and alcohol abuse/use of drugs were associated with death at follow-up, while in multivariate analysis serum creatinine level, vascular disease and previous major bleeding were independent predictors of mortality at follow-up (Table 5).

The actual annual rate (periprocedural and follow-up period) of stroke was $1.2 \%$, and of thromboembolism $2.2 \%$, while the expected annual thromboembolism risk was calculated by the $\mathrm{CHA}_{2} \mathrm{DS}_{2}$-VASc score at $4 \%$, which translates into a $45 \%$ risk reduction (Figure 5 ).

The observed annual major bleeding rate (periprocedural and follow-up period) was $2 \%$ and the annual risk of bleeding estimated by the HAS-BLED score was $3.7 \%$ ( $46 \%$ reduction).

Medication at last follow-up was limited to acetylsalicylic acid in $65 \%$ of patients, while only $10 \%$ of them were under anticoagulant therapy (Figure 2B). In detail, medication used in patients

A

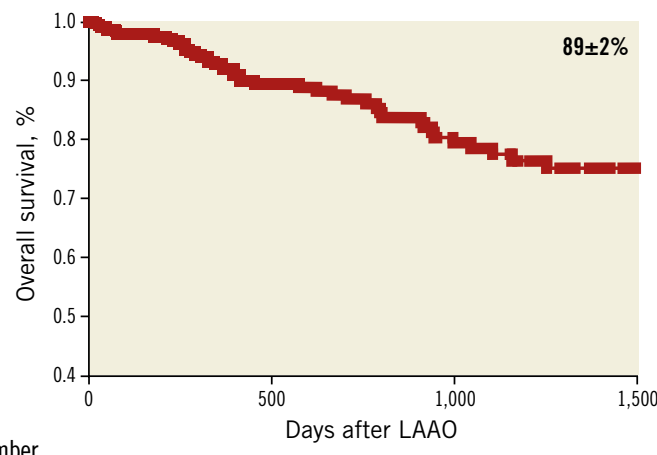

Table 4. Causes of death at follow-up.

\begin{tabular}{|l|c|}
\hline \multicolumn{1}{|c|}{ Cause of death at follow-up } & Number \\
\hline Total & 49 \\
\hline Cardiovascular & 23 \\
\hline Heart failure & 6 \\
\hline Sudden death & 4 \\
\hline Stroke & 1 \\
\hline Myocardial infarction & 1 \\
\hline Device embolisation & 1 \\
\hline Mesenteric infarction & 1 \\
\hline Unknown & 9 \\
\hline Non-cardiovascular & 26 \\
\hline Sepsis & 14 \\
\hline Liver cirrhosis & 3 \\
\hline Cancer & 6 \\
\hline Acute abdomen & 1 \\
\hline ARDS & 1 \\
\hline Suicide & 1 \\
\hline ARDS: acute respiratory distress syndrome & \\
\hline
\end{tabular}

of Group 1 vs. Group 2 was OAC (5 vs. 6), NOAC (10 vs. 15), aspirin (207 vs. 63 ), DAPT (38 vs. 13), clopidogrel (9 vs. 4), combination ( 1 vs. 5), and nothing (14 vs. 10 patients), respectively.

B

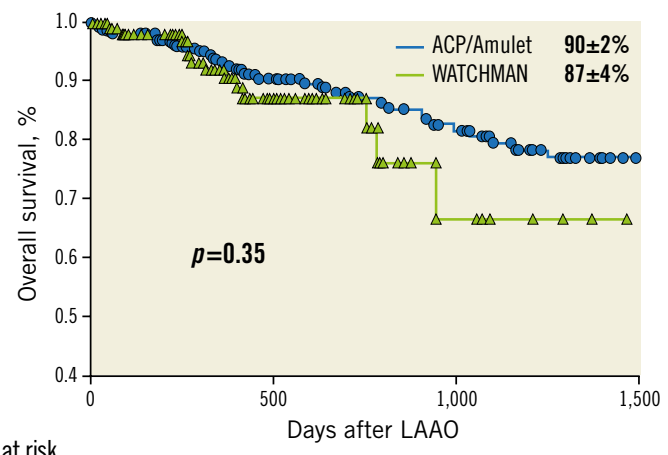

Number at risk

$\begin{array}{lllll}\text { ACP/Amulet } & 293 & 125 & 83 & 43\end{array}$

WATCHMAN $124 \quad 43 \quad 8$

Figure 3. Overall survival after LAAO. A) Kaplan-Meier analysis showing the overall survival of the total cohort. B) Comparison of the overall survival between Group 1 and Group 2.

Table 3. Adverse events during follow-up.

\begin{tabular}{|l|c|c|c|c|c|c|c|}
\hline \multicolumn{1}{|c|}{ Characteristics } & & $\begin{array}{c}\text { All } \\
\text { N=417 }\end{array}$ & $\begin{array}{c}\text { ACP } \\
\text { N=161 }\end{array}$ & $\begin{array}{c}\text { Amulet } \\
\text { N=132 }\end{array}$ & $\begin{array}{c}\text { Group 1 } \\
\text { ACP+Amulet } \\
\text { N=293 }\end{array}$ & $\begin{array}{c}\text { Group 2 } \\
\text { WATCHMAN } \\
\text { N=124 }\end{array}$ & $\begin{array}{c}\text { p-value } \\
\text { MAE follow-up }\end{array}$ \\
\hline Stroke & $\mathrm{n}(\%)$ & $75(17.9)$ & $39(24.2)$ & $16(12.1)$ & $55(18.7)$ & $20(16.1)$ & 0.57 \\
\hline TIA & $\mathrm{n}(\%)$ & $7(1.7)$ & $5(3.1)$ & $1(0.7)$ & $6(2)$ & $1(0.8)$ & 0.67 \\
\hline Major bleeding & $\mathrm{n}(\%)$ & $9(2.1)$ & $2(1.2)$ & $3(2.2)$ & $5(1.7)$ & $4(3.2)$ & 0.46 \\
\hline Death & $\mathrm{n}(\%)$ & $49(11.7)$ & $27(16)$ & $9(7)$ & $36(12)$ & $13(10)$ & 0.73 \\
\hline \multicolumn{2}{|l|}{ ACP: AMPLATZER Cardiac Plug; TIA: transient ischaemic attack } \\
\hline
\end{tabular}


A

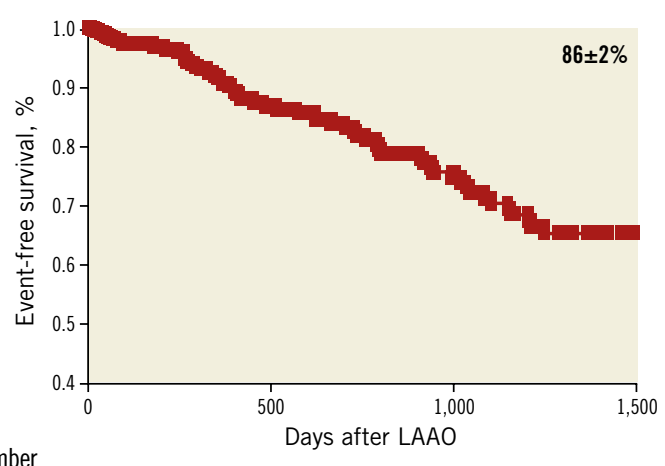

B

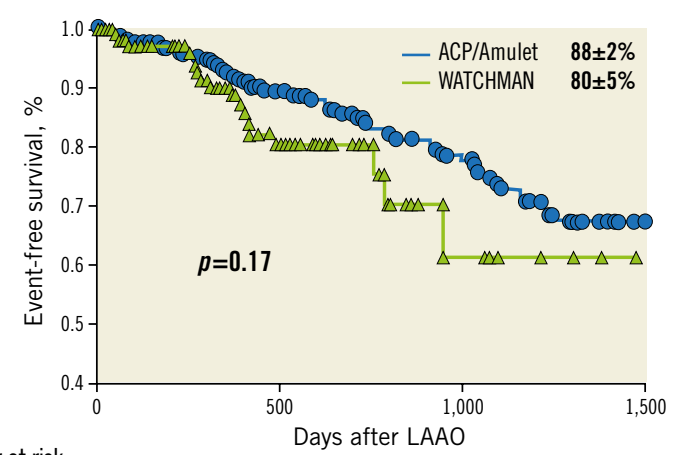

Number at risk

$\begin{array}{lllll}\text { ACP/Amulet } & 293 & 125 & 83 & 43\end{array}$

Figure 4. Event-free survival after LAAO. A) Kaplan-Meier analysis showing the event-free survival of the total cohort. B) Comparison of the event-free survival between Group 1 and Group 2.

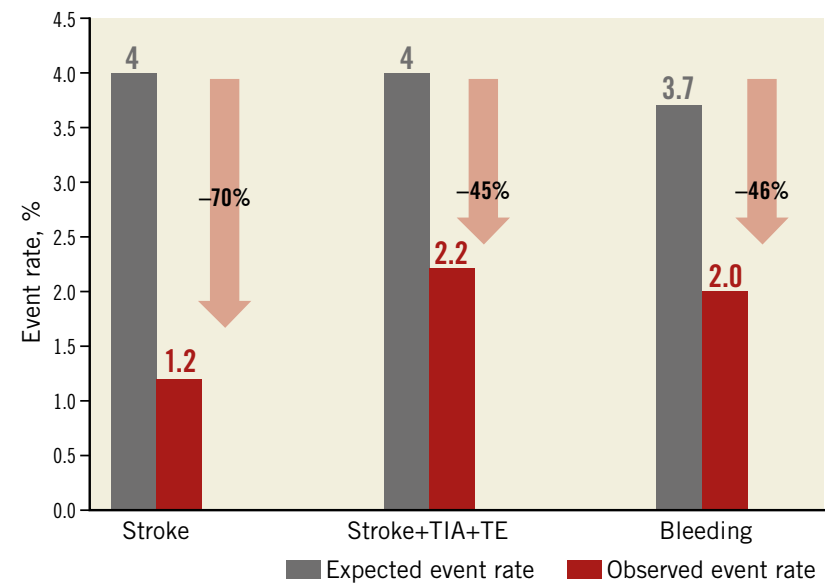

Figure 5. Effectiveness of LAAO in reduction of thromboembolism and bleeding based on annual rate predicted by $C H A A_{2} D S_{2}-V A S c$ and the $H A S-B L E D$ score. Observed event rate in red; expected event rate in grey. TE: thromboembolism

Table 5. Univariate and multivariate analysis for predictors of survival according to Cox models.

\begin{tabular}{|c|c|c|c|c|}
\hline \multirow{2}{*}{ Parameter } & \multicolumn{2}{|c|}{ Univariate analysis } & \multicolumn{2}{|c|}{ Multivariate analysis } \\
\hline & HR (95\% CI) & $p$-value & HR (95\% CI) & $p$-value \\
\hline Age & $1.03(0.99-1.07)$ & 0.16 & & \\
\hline Permanent atrial fibrillation & $0.99(0.56-1.75)$ & 0.97 & & \\
\hline Serum creatinine level & $1.43(1.21-1.71)$ & $<0.001$ & $1.36(1.12-1.64)$ & 0.002 \\
\hline Congestive heart failure & $2.48(1.40-4.4)$ & 0.002 & & \\
\hline Hypertension & $1.28(0.64-2.59)$ & 0.48 & & \\
\hline Age $\geq 75$ years & $1.26(0.70-2.25)$ & 0.44 & & \\
\hline Diabetes & $1.08(0.59-1.9)$ & 0.81 & & \\
\hline Previous stroke/TIA & $0.84(0.47-1.49)$ & 0.55 & & \\
\hline Vascular disease & $2.96(1.64-5.34)$ & $<0.001$ & $2.36(1.26-4.40)$ & 0.007 \\
\hline Age (between 65 and 74) & $1.10(0.61-1.97)$ & 0.76 & & \\
\hline Sex category (female gender) & $1.32(0.75-2.33)$ & 0.34 & & \\
\hline Total $\mathrm{CHA}_{2} \mathrm{DS}_{2}$-VASc score & $1.23(1.04-1.45)$ & 0.01 & & \\
\hline Previous major bleeding & $2.72(1.53-4.84)$ & 0.001 & $2.14(1.16-3.95)$ & 0.016 \\
\hline Alcohol/drug & $1.91(1.06-3.45)$ & 0.032 & & \\
\hline Total HAS-BLED score & $1.38(1.09-1.74)$ & 0.006 & & \\
\hline
\end{tabular}




\section{Discussion}

The main findings of this paper are:

1. The efficacy of LAAO in stroke prevention is very high in reallife settings.

2. The bleeding rate after LAAO, especially the haemorrhagic stroke rate $(0.2 \%$ /year $)$, was lower than expected.

3. The procedure of LAAO is relatively safe in Belgium, with a $4.1 \%$ rate of periprocedural MAE.

4. The outcome of patients undergoing LAAO in real life was similar regardless of the type of device used.

\section{EFFICACY IN STROKE REDUCTION}

Two randomised trials ${ }^{3,6}$ showed the non-inferiority of LAAO using the WATCHMAN device as compared with warfarin. The ACP multicentre registry ${ }^{9}$ showed a thromboembolism rate after LAAO of $2.3 \%$ among patients with a $\mathrm{CHA}_{2} \mathrm{DS}_{2}$-VASc score of 4.5. The thromboembolism rate after WATCHMAN implantation in the ASAP registry including patients contraindicated for $\mathrm{OAC}^{22}$ was $2.3 \%$ (mean $\mathrm{CHA}_{2} \mathrm{DS}_{2}$-VASc score of 4.4 ). The effectiveness in terms of cardioembolic event reduction was similar in our study: the observed stroke rate was $1.2 \%$, and the thromboembolism rate was $2.2 \%$, which translates into a $45 \%$ risk reduction for patients with a mean $\mathrm{CHA}_{2} \mathrm{DS}_{2}$-VASc score of 4.0 .

\section{IMPACT ON BLEEDING}

The bleeding rate observed after LAAO in Belgium was $2 \%$, while the expected bleeding rate was $3.7 \%$. Only two haemorrhagic strokes were observed during the follow-up period (haemorrhagic stroke rate $0.2 \% /$ year), despite the fact that $29 \%$ of our population experienced an intracranial bleeding before the procedure. The rate of major bleeding in the new oral anticoagulants (NOACs) trials was $4.5 \%$ in the ROCKET ${ }^{23}, 2.7 \%$ in the RELY ${ }^{24}$ and $2.1 \%$ in the ARISTOTLE trial ${ }^{25}$, while the rates of haemorrhagic stroke were $0.3,0.1$ and $0.2 \%$ /year, respectively. In the Belgian LAAO registry, $90 \%$ of patients were left untreated by any form of OAC at last follow-up, potentially explaining the lower rate of bleeding as compared with NOAC trials, despite the fact that the latter trials included patients with a lower risk profile than in our real-life study.

\section{PROCEDURAL SAFETY}

The rate of MAE (4.1\%) in our study is lower than in the initial ACP European registry ${ }^{4}$ or the PROTECT AF study ${ }^{3}$ (7.3 and $7.7 \%$ MAE, respectively), and is similar to those in the more recent publications ${ }^{6,7,9}$, such as the CAP (3.7\%), multicentre ACP registry (4.9\%) and PREVAIL study (4.2\%). The Belgian LAAO registry included all the procedures performed in all the centres (the first implants were not excluded). There was a wide range of number of implants per centre (three had more than 50 procedures while 10 others had less than 10). In our study, all the first cases in each institution were performed with an on-site proctor, explaining better results, compared to the initial experience ${ }^{3,4}$. Periprocedural mortality was similarly low at $0.6 \%$ and $0.7 \%$ in the Belgian and in the EWOLUTION registries, respectively.
As an elective and preventive procedure, these upfront risks must be taken into account for LAAO indication and must be weighed against serious bleeding issues when using (N)OAC.

\section{DEVICE COMPARISON}

To the best of our knowledge, the Belgian LAAO registry is the national registry with the highest number of patients, comparing three devices, namely ACP, Amulet and WATCHMAN. Betts et $\mathrm{al}^{16}$ reported the experience in the United Kingdom among 371 patients treated with the WATCHMAN, ACP, LARIAT (SentreHEART, Redwood City, CA, USA) or Coherex WaveCrest $^{\circledR}$ (Biosense Webster, Inc., Irvine, CA, USA) devices, followed during a mean period of 24 months: they stated that the procedure is safe and successful regardless of the technology used but without side-by-side comparison of the devices. Our study compared baseline, procedural and follow-up data on 457 patients treated with ACP, Amulet or WATCHMAN, followed during a mean period of 20 months. Except for major bleedings during the periprocedural period, we showed that the outcome was similar after LAAO, using either the WATCHMAN or the ACP/Amulet device.

\section{Limitations}

This registry has an observational design limited by several factors: - the centres included their data by themselves with no core lab, especially for the neurological evaluation in case of stroke and TIA

- the follow-up is limited to the clinical evaluation without noninvasive imaging information.

\section{Conclusions}

The Belgian LAAO registry showed that the procedure is relatively safe, and reduces the thromboembolism and the bleeding rates as compared with the expected risks calculated by the $\mathrm{CHA}_{2} \mathrm{DS}_{2}$-VASc and HAS-BLED score, respectively. It is important to emphasise that the observed rate of cerebral haemorrhage was very low at $0.2 \%$ /year in our registry, despite one third of this real-life population of patients having experienced a prior intracranial bleeding before the procedure. The overall and event-free survival was similar after LAAO in Belgium, regardless of the type of device used (ACP, Amulet or WATCHMAN). These data may support further studies, using one of these prostheses, evaluating NOAC versus LAAO to compare the impact on the clinical outcome and the cost-effectiveness of these two strategies among AF patients at high risk for stroke.

\section{Impact on daily practice}

The data of the Belgian left atrial appendage occlusion registry suggest that the procedure is safe and effective in a realworld setting, for atrial fibrillation-related thromboembolism prevention using either the WATCHMAN or the ACP/Amulet device. 


\section{Conflict of interest statement}

J. Kefer, W. Budts and A. Aminian are proctors for St. Jude Medical. A. Aminian is proctor for Boston Scientific. The other authors have no conflicts of interest to declare.

\section{References}

1. Sievert H, Lesh MD, Trepels T, Omran H, Bartoelli A, Della Bella P, Nakai T, Reisman M, DiMario C, Block P, Kramer P, Fleschenberg D, Krumsdorf U, Scherer D. Percutaneous left atrial appendage transcatheter occlusion to prevent stroke in high-risk patients with atrial fibrillation: early clinical experience. Circulation. 2002;105:1887-9.

2. Block PC, Burstein S, Casale PN, Kramer PH, Teirstein P, Williams DO, Reisman M. Percutaneous left atrial appendage occlusion for patients in atrial fibrillation suboptimal for warfarin therapy: 5-year results of the PLAATO (Percutaneous Left Atrial Appendage Transcatheter Occlusion) Study. J Am Coll Cardiol. 2009;2:594-600.

3. Holmes DR, Reddy VY, Turi ZG, Doshi SK, Sievert H, Buchbinder M, Mullin CM, Sick P; PROTECT AF Investigators. Percutaneous closure of the left atrial appendage versus warfarin therapy for prevention of stroke in patients with atrial fibrillation: a randomised non-inferiority trial. Lancet. 2009;374:534-42.

4. Park JW, Bethencourt A, Sievert H, Santoro G, Meier B, Walsh K, Lopez-Minguez JR, Meerkin D, Valdés M, Ormerod O, Leithäuser B. Left atrial appendage closure with Amplatzer cardiac plug in atrial fibrillation: initial European experience. Catheter Cardiovasc Interv. 2011;77:700-6.

5. Reddy VY, Sievert H, Halperin J, Doshi SK, Buchbinder M, Neuzil P, Huber K, Whisenant B, Kar S, Swarup V, Gordon N, Holmes D; PROTECT AF Steering Committee and Investigators. Percutaneous left atrial appendage closure vs warfarin for atrial fibrillation: a randomized clinical trial. JAMA. 2014;312:1988-98.

6. Holmes DR Jr, Kar S, Price MJ, Whisenant B, Sievert H, Doshi SK, Huber K, Reddy VY. Prospective randomized evaluation of the Watchman Left Atrial Appendage Closure device in patients with atrial fibrillation versus long-term warfarin therapy: the PREVAIL trial. J Am Coll Cardiol. 2014;64:1-12.

7. Reddy VY, Holmes D, Doshi S, Neuzil P, Kar S. Safety of percutaneous left atrial appendage closure: results from the Watchman Left Atrial Appendage System for Embolic Protection in Patients with AF (PROTECT AF) clinical trial and the Continued Access Registry. Circulation. 2011;123:417-24.

8. Boersma LV, Schmidt B, Betts TR, Sievert H, Tamburino C, Teiger E, Pokushalov E, Kische S, Schmitz T, Stein KM, Bergmann MW; EWOLUTION investigators. Implant success and safety of left atrial appendage closure with the WATCHMAN device: Periprocedural outcomes from the EWOLUTION registry. Eur Heart J. 2016;37:2465-74.

9. Tzikas A, Shakir S, Gafoor S, Omran H, Berti S, Santoro G, Kefer J, Landmesser U, Nielsen-Kudsk JE, Cruz-Gonzalez I, Sievert H, Tichelbäcker $T$, Kanagaratnam $P$, Nietlispach F, Aminian A, Kasch F, Freixa X, Danna P, Rezzaghi M, Vermeersch P,
Stock F, Stolcova M, Costa M, Ibrahim R, Schillinger W, Meier B, Park JW. Left atrial appendage occlusion for stroke prevention in atrial fibrillation: multicentre experience with the AMPLATZER Cardiac Plug. EuroIntervention. 2016;11:1170-9.

10. Kefer J, Vermeersch P, Budts W, Depotter T, Aminian A, Benit E, Stammen F. Transcatheter left atrial appendage closure for stroke prevention in atrial fibrillation with Amplatzer cardiac plug: the Belgian Registry. Acta Cardiol. 2013;68:551-8.

11. López Mínguez JR, Asensio JM, Gragera JE, Costa M, González IC, de Carlos FG, Díaz JA, Martín Yuste V, González RM, Domínguez-Franco A, Buendía AB, Garibi JH, Hernández FH, Ribeiro VG. Two-year clinical outcome from the Iberian registry patients after left atrial appendage closure. Heart. 2015;101:877-83.

12. Boersma LV, Ince $H$, Kische $S$, Pokushalov E, Schmitz T, Schmidt B, Gori T, Meincke F, Protopopov AV, Betts T, Foley D, Sievert H, Mazzone P, De Potter T, Vireca E, Stein K, Bergmann MW; EWOLUTION Investigators. Efficacy and safety of left atrial appendage closure with WATCHMAN in patients with or without contraindication to oral anticoagulation: 1-Year follow-up outcome data of the EWOLUTION trial. Heart Rhythm. 2017;14:1302-8.

13. Bergmann MW, Betts TR, Sievert H, Schmidt B, Pokushalov E, Kische S, Schmitz T, Meincke F, Stein KM, Boersma LV, Ince H. Safety and efficacy of early anticoagulation drug regimens after WATCHMAN left atrial appendage closure: three-month data from the EWOLUTION prospective, multicentre, monitored international WATCHMAN LAA closure registry. EuroIntervention. 2017;13:877-84.

14. Phillips KP, Walker DT, Humphries JA. Combined catheter ablation for atrial fibrillation and Watchman ${ }^{\circledR}$ left atrial appendage occlusion procedures: Five-year experience. J Arrhythm. 2016;32: 119-26.

15. Kim JS, Lee H, Suh Y, Pak HN, Hong GR, Shim CY, Yu CW, Lee HJ, Kang WC, Shin ES, Choi RK, Kar S, Park JW, Lim DS, Jang Y. Left Atrial Appendage Occlusion in Non-Valvular Atrial Fibrillation in a Korean Multi-Center Registry. Circ J. 2016; 80:1123-30.

16. Betts TR, Leo M, Panikker S, Kanagaratnam P, Koa-Wing M, Davies DW, Hildick-Smith D, Wynne DG, Ormerod O, Segal OR, Chow AW, Todd D, Cabrera Gomez S, Kirkwood GJ, Fox D, Pepper C, Foran J, Wong T. Percutaneous left atrial appendage occlusion using different technologies in the United Kingdom: A multicenter registry. Catheter Cardiovasc Interv. 2017;89: 484-92.

17. Tzikas A, Holmes DR Jr, Gafoor S, Ruiz CE, BlomströmLundqvist C, Diener HC, Cappato R, Kar S, Lee RJ, Byrne RA, Ibrahim R, Lakkireddy D, Soliman OI, Näbauer M, Schneider S, Brachman J, Saver JL, Tiemann K, Sievert H, Camm AJ, Lewalter T. Percutaneous left atrial appendage occlusion: the Munich consensus document on definitions, endpoints and data collection requirements for clinical studies. EuroIntervention. 2016;12:103-11.

18. Leon MB, Piazza N, Nikolsky E, Blackstone EH, Cutlip DE, Kappetein AP, Krucoff MW, Mack M, Mehran R, Miller C, Morel MA, Petersen J, Popma JJ, Takkenberg JJ, Vahanian A, van 
Es GA, Vranckx P, Webb JG, Windecker S, Serruys PW. Standardized endpoint definitions for transcatheter aortic valve implantation clinical trials: a consensus report from the Valve Academic Research Consortium. Eur Heart J. 2011;32:205-17.

19. Mehran R, Rao SV, Bhatt DL, Gibson CM, Caixeta A, Eikelboom J, Kaul S, Wiviott SD, Menon V, Nikolsky E, Serebruany V, Valgimigli M, Vranckx P, Taggart D, Sabik JF, Cutlip DE, Krucoff MW, Ohman EM, Steg PG, White H. Standardized bleeding definitions for cardiovascular clinical trials. a consensus report from the Bleeding Academic Research Consortium. Circulation. 2011;123:2736-47.

20. Lip GY, Nieuwlaat R, Pisters R, Lane DA, Crijns HJ. Refining clinical risk stratification for predicting stroke and thromboembolism in atrial fibrillation using a novel risk factorbased approach: the euro heart survey on atrial fibrillation. Chest. 2010;137:263-72.

21. Lip GY, Frison L, Halperin JL, Lane DA. Comparative validation of a novel risk score for predicting bleeding risk in anticoagulated patients with atrial fibrillation: the HAS-BLED (Hypertension, Abnormal Renal/Liver Function, Stroke, Bleeding, History of Predisposition, Labile INR, Elderly, Drugs/Alcohol Concomitantly) score. J Am Coll Cardiol. 2011;57:173-80.

22. Reddy VY, Möbius-Winkler S, Miller MA, Neuzil P, Schuler G, Wiebe J, Sick P, Sievert H. Left atrial appendage closure with the Watchman device in patients with a contraindication for oral anticoagulation: the ASAP study (ASA Plavix Feasibility Study With Watchman Left Atrial Appendage Closure Technology). J Am Coll Cardiol. 2013;61:2551-6.

23. Patel MR, Mahaffey KW, Garg J, Pan G, Singer DE, Hacke W, Breithardt G, Halperin JL, Hankey GJ, Piccini JP, Becker RC, Nessel CC, Paolini JF, Berkowitz SD, Fox KA, Califf RM; ROCKET AF Investigators. Rivaroxaban versus warfarin in atrial fibrillation. N Engl J Med. 2011;365:883-91.

24. Connolly SJ, Ezekowitz MD, Yusuf S, Eikelboom J, Oldgren J, Parekh A, Pogue J, Reilly PA, Themeles E, Varrone J, Wang S, Alings M, Xavier D, Zhu J, Diaz R, Lewis BS, Darius H, Diener HC, Joyner CD, Wallentin L; RE-LY Steering Committee and Investigators. Dabigatran versus warfarin in patients with atrial fibrillation. N Engl J Med. 2009;361:1139-51.

25. Granger CB, Alexander JH, McMurray JJ, Lopes RD, Hylek EM, Hanna M, Al-Khalidi HR, Ansell J, Atar D, Avezum A, Bahit MC, Diaz R, Easton JD, Ezekowitz JA, Flaker G, Garcia D, Geraldes M, Gersh BJ, Golistyn S, Goto S, Hermosillo AG, Hohnloser SH, Horowitz J, Mohan P, Jansky P, Lewis BS, LopezSendon JL, Pais P, Parkhomenko A, Verheugt FW, Zhu J, Wallentin L; ARISTOTLE Committees and Investigators. Apixaban versus warfarin in patients with atrial fibrillation. $N$ Engl J Med. 2011;365:981-92. 